\title{
Kuhn, relativism and realism
}

\section{Introduction}

The historian of science, Thomas S. Kuhn (1922-1996), was one of the most influential figures in the history and philosophy of science in the latter half of the twentieth century. His model of scientific theory change contains a number of relativistic and anti-realist elements. In this chapter, my aim is to explore the relationship between Kuhn's views about the nature of science and the position of scientific realism.

I will understand scientific realism in what I take to be a classical sense. According to scientific realism, the aim of science is to discover the truth about the objective reality which we inhabit. Progress in science consists in advance toward this aim. Scientific investigation is not restricted to observable phenomena. It extends beyond the domain of the observable to include dimensions of reality that are not observable by unaided human sense perception. Theoretical claims are to be taken at face value as claims which purport to be about real unobservable features of reality. They are not to be reduced to discourse about observables. Truth is to be understood in a non-epistemic correspondence sense. It is the way things stand in the mind-independent, objective world that makes scientific claims about the world true or false. When a claim about the world is true, it is because it corresponds to the way the world actually is. (For more detail on scientific realist views of truth, see the entry by Jamin Asay on Realism and Theories of Truth.)

Before I turn to the relativist and anti-realist themes in Kuhn, I will present a brief overview of the key features of Kuhn's account of science. 


\section{Kuhn's model of scientific change}

Kuhn's masterwork, The Structure of Scientific Revolutions, was first published in 1962 (reference here will be to the $4^{\text {th }}$ edition, published in 2012). Structure, as the book is widely known, is the signal work in the historical turn which took hold in the philosophy of science during the 1960s and 70s. Earlier empiricist philosophers of science explored such topics as empirical verification, formal relations between evidence and theory, and the methodology of science. By contrast, advocates of the historical approach to the philosophy of science chose to concentrate on the actual processes of scientific change found in the historical record of past science.

Rather than offer a theory of scientific method, Kuhn proposed a model of scientific change. In the early stages of the development of a science, research in a particular field tends to be disunified as individual scientists pursue a range of competing approaches to their field. Writing of physical optics before Newton, Kuhn says that "though the field's practitioners were scientists, the net result of their activity was something less than science”; as such, they were unable to take any "common body of belief for granted” (2012:13). Eventually, however, consensus does form around a shared body of evidence, basic theoretical principles and strategies for the conduct of research. The focus of such consensus is what Kuhn referred to as a "paradigm". Paradigms are "universally recognized scientific achievements" (2012: xlii) which serve as the basis for "coherent traditions of scientific research” (2012: 11).

A science which acquires a paradigm thereby arrives at a state of maturity. Mature scientific research based on a shared paradigm is characterized by a unity of opinion that is substantive and normative in nature. Acceptance of a paradigm brings with it agreement on 
law and theory, as well as an agenda of research "puzzles" that are to be addressed on the basis of the paradigm. Puzzles, which may be empirical or theoretical, include precise determination of significant fact, rigorous comparison of prediction with observation and extension of the paradigm to new phenomena and domains. The paradigm provides scientists with methodological standards which take the form of rules of puzzle-solving adequacy that acceptable puzzle-solutions must satisfy. The rules include the basic laws of the paradigm, such as Newton’s laws, which "help to set puzzles and to limit acceptable solutions” (2012: 40). Low-level rules govern the use of instrumentation and the conduct of experiment. Underlying metaphysical commitments of a paradigm (e.g. corpuscularism) serve as higher level rules which tell scientists not only what exists but what "fundamental explanations must be like” (2012: 41).

Kuhn describes science devoted to puzzle-solving on the basis of a shared paradigm as "normal science". It is characterized by routinized solution of puzzles on the basis of the agreed rules of puzzle-solving adequacy. Progress within a paradigm consists in an increase in solved puzzles and is highly cumulative in nature. Normal scientific puzzle-solving is the activity most typical of the sciences. As Kuhn notes, it is "the activity in which most scientists inevitably spend almost all their time” (2012: 5). But the success of normal science may lead to its own undoing. In time, the paradigm may encounter "anomalies", which, unlike the puzzles of normal science, stubbornly resist solution. If these anomalies proliferate or become particularly acute, scientists may lose confidence in the ability of the paradigm to resolve all of the problems in their field. Such lack of confidence may generate a “crisis” in which scientists actively raise doubts about the paradigm. During such a crisis period, scientists develop and propose alternative candidates for paradigm. A debate may ensue between those scientists who continue to support the reigning paradigm and those who favour one of the emerging candidates for paradigm. 
Some of Kuhn's most controversial ideas have to do with paradigm debate. Adherents of competing paradigms are at "least slightly at cross-purposes" and are "bound partly to talk through each other”, since their paradigms are “incommensurable” (2012: 147). Though in his later work the notion is restricted to semantic relations between theories, in Structure Kuhn outlined a number of different aspects of the incommensurability of competing paradigms. The first has a methodological dimension. Competing paradigms employ different methodological standards and seek to address different sets of puzzles. The second aspect is broadly semantic. Each paradigm adopts a different conceptual framework, which gives rise to semantic variation between the vocabularies employed by the competing paradigms. The third aspect relates to perception but may have an ontological dimension. As Kuhn puts the point, "the proponents of competing paradigms practice their trades in different worlds ... Practicing in different worlds, the two groups of scientists see different things when they look from the same point in the same direction” (2012: 149). With this third aspect of incommensurability, Kuhn may simply be understood as making the point that observation is theory-dependent, and so varies with paradigm. But, as will be noted later, it may also serve as the basis of an anti-realist interpretation of Kuhn’s model.

Despite incommensurability, scientists do ultimately choose between paradigms. If they reject the old paradigm in favour of a new one, science may return to normal science under the auspices of the new paradigm. When this happens a "scientific revolution" has taken place. For Kuhn, revolution occurs when an old paradigm is rejected by the members of a scientific community and a new paradigm is adopted as the basis for a further period of normal science. There is no reason to expect such a pattern of repeated transition between periods of normal science to go on forever. Still, Kuhn's model does suggest that scientific change is to some extent cyclical. 
This overview of Kuhn's model of scientific change will serve as a basis on which to introduce the topics of the following sections. Because the standards of theory appraisal vary with paradigm, Kuhn's model seems to carry with it a relativistic view of methodological standards. In section three, I will bring this aspect of Kuhn's model into contact with relevant aspects of scientific realism. I will then turn to the question of progress and truth. Kuhn's model is a problem-solving model that proceeds by way of puzzles and anomalies rather than progress toward truth. In section four, I will explore Kuhn's views about the nature of scientific progress in connection with scientific realist views about truth and the nature of scientific progress. This will lead in section five to consideration of Kuhn's views about the incommensurability of paradigms, as well as brief consideration of an anti-realist interpretation of his talk of world-change. In section six, I will conclude by indicating that the scientific realist may endorse some aspects of Kuhn's view.

\section{Kuhn's epistemic relativism and scientific realism}

In this section, I will explore the relationship between epistemic relativist aspects of Structure and the position of scientific realism. Relativism is often contrasted with realism. But not all forms of relativism are opposed to all forms of realism. The question therefore arises of whether and how scientific realism enters into conflict with epistemic relativism as it appears in Kuhn. Scientific realism as characterized here is not formulated as a theory about the nature of norms of theory appraisal. As such, it does not enter into immediate conflict with Kuhn's views about the variation of such norms. However, as we shall see, it is possible to bring out a conflict between the positions if an account of the norms of theory appraisal is added to scientific realism. 
Epistemic relativism is relativism about epistemic justification and knowledge. It is the view that justified belief and knowledge are relative to epistemic norms which are subject to variation with context (e.g. historical time period, socio-cultural milieu, scientific paradigm). My concern in this section will be with epistemic justification rather than knowledge. The reason for this restriction is that knowledge requires truth as well as epistemic justification. I will focus on epistemic relativism only insofar as it entails relativism about epistemic justification rather than truth. I narrow the focus in this way because I wish to postpone consideration of Kuhn's views about truth until the next section.

According to Kuhn, the primary concern of normal science is to solve puzzles that arise in the application and development of a paradigm. The paradigm provides scientists with standards of puzzle-solving adequacy which they use to determine whether the puzzles that arise in normal-scientific research are satisfactorily resolved. Because normal science is founded on consensus on paradigm, as well as standards of appraisal that derive from the paradigm, the practice of normal science is characterized by widespread consensus. In effect, scientists who work within the same paradigm share a common set of epistemic norms on the basis of which their beliefs about matters relating to the paradigm may be justified.

By contrast with normal science, the period of crisis and extraordinary science which leads to revolutionary transition between paradigms manifests divergence with respect to epistemic norms. Scientists who favour an alternative paradigm-candidate thereby reject the standards embedded in the reigning paradigm. New standards of puzzle-solving adequacy are introduced in the context of the alternative paradigm-candidate. But, while the standards depend upon and vary with paradigm, there is no set of extra-paradigmatic standards to which appeal may be made in order to arbitrate between competing paradigms. Given the absence of neutral standards of theory choice, Kuhn draws an explicit comparison between revolutionary choice of scientific paradigm and political revolution. As he famously put the 
point, "As in political revolutions, so in paradigm choice - there is no standard higher than the assent of the relevant community” (2012: 94).

A number of early critics took Kuhn's account of paradigm choice to contain elements of relativism and irrationalism (e.g. Lakatos 1970; Popper 1970; Shapere 1964). On the one hand, each paradigm contains standards of puzzle-solving adequacy which provide scientists who work within a paradigm with epistemic norms on the basis of which their beliefs may be justified. On the other hand, Kuhn denies that there are extra-paradigmatic standards on the basis of which the choice between competing paradigms may be made. In the absence of extra-paradigmatic standards, the choice between paradigms seems unable to be made on a rational basis. The impression of irrationalism is reinforced by comments made by Kuhn in which he compares the choice between paradigms to a gestalt switch or religious conversion (2012: 149). On the picture of paradigm choice that emerges from Structure, epistemic justification is relative to the standards of puzzle-solving adequacy that operate within a paradigm, though the choice of paradigm may not itself be rationally based.

The perceived irrationalism and relativism of Kuhn's account of paradigm change lent Structure an air of controversy. Early critics reacted strongly. But more moderate interpretations of Kuhn have since come to prevail. Though not without foundation in the text of Structure, the early critical reaction now seems exaggerated. In later work, Kuhn sought to distance himself from the extreme view that the early critical reaction found in Structure. Despite his apparent denial of fixed or universal methodological norms, Kuhn made passing reference in Structure to "commitments without which no man is a scientist" (2012: 42). However, he did not at that stage fully articulate those commitments. This was a task to which he later turned in response to the early criticism. He outlines the less extreme view in the Postscript - 1969 appended to the second and later editions of Structure. The 
most detailed statement of the position is to be found in "Objectivity, Value Judgment and Theory Choice” (1977).

In contrast with his earlier apparent denial of extra-paradigmatic standards, in this later work Kuhn claimed that there are a number of standards of theory-appraisal found throughout the sciences. His main examples of such standards are accuracy, consistency, breadth, simplicity and fruitfulness, a list that he does not take to be exhaustive (1977: 3212). Though subject to some qualification, Kuhn allows that these standards are "permanent attributes of science” (1977: 335). When faced with a choice between competing paradigms, scientists appeal to these standards as the basis for comparative assessment of the paradigms. The standards "provide the shared basis for theory choice” (1977: 322). As such, the standards constitute extra-paradigmatic norms of theory-appraisal on the basis of which scientists are able to make a rational choice between competing paradigms.

But while the standards provide a basis for theory choice, there are limits on their capacity to determine a choice. The existence of such extra-paradigmatic norms does not guarantee a unique or unequivocal choice of paradigm. Kuhn pointed out that the individual standards are subject to variant interpretation. Scientists may understand the standards differently. As a result, different scientists may apply the same standards in different ways. Moreover, there is the potential for conflict between the standards when applied to competing theories. For example, one theory might be simpler but less accurate than a competitor, or one might have greater breadth but less consistency than another. Given the ambiguity of the standards and potential for conflict between them, Kuhn chose to describe the standards not as rules but as values (1977: 331). Rather than being rules that dictate an unequivocal choice of theory, the standards serve as values which guide scientists in the assessment of competing theories. Kuhn expressed the point by saying that there is no "neutral algorithm of theory choice” (2012: 198). 
In the absence of an algorithm of theory choice, scientists must exercise a capacity for judgement not directed by rule. The decision to adopt one paradigm over another requires a deliberative judgement in which scientists weigh up a diverse range of potentially competing factors. It is possible that they may reach a common decision on the same grounds. But they need not do so. Scientists who agree in choice of paradigm need not arrive at their choice on the same basis. Moreover, scientists who disagree with each other may do so on a rational basis. Scientists who adopt opposing paradigms may do so on a rational basis since their choice may be based on the shared standards of scientific theory choice.

With this as background, I now turn to the relation of Kuhn's view of theory choice to scientific realism. I will focus on the epistemic relativist aspects of Kuhn's view rather than his denial of an algorithm of theory choice. The reason for this is that there is no apparent need for the realist to deny that the appraisal of theories is based on a range of methodological considerations or to insist on an algorithm of theory choice. As for the epistemic relativism found by early critics in Structure, the question is how it connects with scientific realism. On the characterization that I have given of scientific realism, there is no commitment on the part of the scientific realist to any claim about the nature or function of scientific methodology. One advantage of such a characterization is that it leaves it open for the realist to adopt a view of the practice of science that plays down or denies altogether the role of methodological factors. Still, as I will now proceed to argue, it is possible to bring scientific realism into more direct conflict with epistemic relativism.

A realist might downplay or deny the role of methodological factors in choice of theory. But this is not the usual approach. Most philosophers of science take the methodology of science seriously. Scientific realists are no exception. Realists tend to grant the norms of scientific method a pivotal role in the appraisal, adoption and even the development of theories. Because they take methodological considerations to play a role in 
relation to theory choice their views with respect to method enter into conflict with the epistemic relativist position.

To see this, let us recall the realist view of the aim of science and the nature of scientific progress. On this view, the aim of science is to discover the truth about the world. With the advance of science, later theories attain a higher degree of truth than earlier theories. The norms of method contribute to the progress of science because of the role they play in choice of theory. Scientists base their choice of theory on norms of theory appraisal. That choice results in advance on truth. As a result, increase in truth is due to the use made by scientists of the norms of theory appraisal. Given the role they play in the advance on truth, the norms perform an epistemic function. Use of the norms of scientific theory appraisal reliably leads scientists closer to the truth. If not an infallible indicator of truth, the norms at least have the capacity to exclude false theories in favour of theories that have a good prospect of being true.

Given the role played by norms of theory appraisal, realism entails the truthconducive nature of those norms. The norms constitute a reliable means for the pursuit of truth. We may now see how scientific realism and Kuhn-style epistemic relativism enter into conflict. On a realist construal, the norms of scientific method conduce to truth. But on an epistemic relativist view of the standards of theory-appraisal, there is no commitment to the reliability or truth-conduciveness of the norms of scientific method. They are just norms that have been adopted by social consensus within a scientific community. There is no objective warrant for such norms.

At this point, a clear conflict emerges between scientific realism and the epistemic relativism of Structure. This conflict requires adoption of a realist construal of the norms of theory appraisal as truth-conducive norms of inquiry. In order to bring out this conflict, I 
have appealed to the realist's view of the role of truth in scientific inquiry. But, as we are about to see in the next section, Kuhn's account of science affords little scope for a realist conception of truth.

\section{Kuhn on progress and truth}

As traditionally understood, scientific realism takes the aim of science to be truth and progress to consist in advance toward that aim. By contrast, Kuhn conceives of science in terms of problem-solving. For him, scientific progress is to be thought of as progress with respect to the solution of problems. In normal science, progress consists in the continued solution of the puzzles that arise within the paradigm. In scientific revolution, the anomalies which brought about a crisis in the old paradigm must be resolved by the new paradigm. Given the emphasis on problem-solving, Kuhn's account of progress in Structure ascribes no role to the notion of truth.

Indeed, Kuhn raises doubts about whether the notion of scientific progress is to be conceived in terms of a goal toward which science progresses. Instead, he notes that the “developmental process" described in Structure is "a process of evolution from primitive beginnings" (2012: 169). As such, progress need not be thought of as "a process of evolution toward anything” (2012: 170). Kuhn recognizes that an evolutionary conception of progress which does not involve progress toward an endpoint may conflict with common assumptions about scientific progress. But he wonders whether it is really necessary to conceive of scientific progress as movement toward "one full, objective, true account of nature” (2012: 170). Once an evolutionary conception of progress is adopted, he suggests, there is no need to think of progress in teleological terms as an advance toward the truth. 
The problem-solving account of progress that Kuhn presents in Structure accords no role to truth. But Kuhn's stance appears to have hardened by the time he wrote the Postscript. Rather than a stance of neutrality, his tone becomes dismissive. He expresses doubt about the very idea of a correspondence between theory and reality. He also sees no historical evidence of convergence on truth in the record of past scientific theory change. As the two points are distinct, I will discuss them separately.

As for the first point, Kuhn considers the idea that successive changes of theory in the history of science give rise to an increasing approximation to the truth. He understands the relevant idea of truth to be a correspondence notion. As he puts it, such a notion of truth involves a 'match ... between the entities with which the theory populates nature and what is "really there”" (2012: 205). For his part, Kuhn holds that little sense can be made of such a notion of truth.

Perhaps there is some other way of salvaging the notion of 'truth' for application to whole theories, but this one will not do. There is, I think, no theoryindependent way to reconstruct phrases like "really there"; the notion of a match between the ontology of a theory and its "real" counterpart in nature now seems to me illusive in principle. (2012: 205)

At first, Kuhn appears to be concerned with whether it is possible to apply the notion of truth to an entire theory rather than the individual assertions entailed by the theory. But the main thrust of his remark seems to relate to the intelligibility of the idea of a correspondence between theory and reality rather than the applicability of the idea at the level of whole theories.

Kuhn's claim that the idea of a match between theory and reality is "illusive in principle" suggests a view that is positivistic in spirit. Such a view might derive support from the point that it is not possible to provide conclusive empirical verification that a match obtains between what a theory says and the way the world is. This point might incline a 
philosopher of positivist persuasion to dismiss the idea of a match between theory and reality as unintelligible. But, unless one harbours such positivistic scruples, it is difficult to see why one might suppose there to be any basis for doubt that coherent sense may be made of a match between theory and reality. If a theory says that the world is a certain way, and the world is indeed that way, then what the theory says matches the way that the world actually is. If the world is not the way the theory says it is, then a match fails to obtain between the theory and reality. This remains the case whether or not it is possible to empirically verify that the relation does or does not obtain. (For detailed analysis of this aspect of Kuhn, see Bird 2000: 225-37.)

Kuhn presents his second point as a historical one. As a historian, he finds it doubtful that theories in a historical sequence converge on truth at the level of ontology. He allows that progress is made with respect to problem-solving ability in the transition from Aristotelian to Newtonian and later Einsteinian physics. But, he says,

I can see in their succession no coherent direction of ontological development. On the contrary, in some important respects, though by no means in all, Einstein's general theory of relativity is closer to Aristotle's than either of them is to Newton's. (2012: 205)

On Kuhn's evolutionary problem-solving account of progress, the transition from Aristotle through to Newton and Einstein may constitute scientific progress. But, at the level of ontology, Kuhn claims that there are respects in which Einstein's theory is closer to Aristotle's than to Newton's. As a result, he maintains that this historical sequence of theories fails to display evidence of ontological convergence. As he later tended to put the point, there is no historical evidence that this sequence of theories is "zeroing in" on the truth (cf. Kuhn 2000: 206, 243).

Kuhn does not explain exactly what ontological differences he has in mind when he insists on lack of ontological convergence. But it seems clear that he takes convergence on 
truth to require that the differences introduced within a historical sequence of theories be no more than refinements within a shared ontological framework. Here two points may be made on behalf of the realist in response to Kuhn. First, it is entirely possible for a theory to make more true claims than another theory even if the theories differ at the level of ontology. Given this, it is entirely possible for one theory to be closer to the truth about the world than the other despite their difference in ontology. Second, there is no need for the realist to be wed to the idea that progress requires convergence on one true theory of the world. All that is required for progress with respect to truth is that there be an increase in the number of truths asserted by a later theory as compared to an earlier theory. (Here it is important to note that technical difficulties have confronted the idea of closeness to the truth. For an overview of the issues, see Psillos 1999, chapter 11.)

Throughout his career, Kuhn remained critical of correspondence conceptions of truth as well as the idea of ontological convergence. However, in later work Kuhn came to see that truth does play a crucial role in science. Though he holds that the correspondence theory of truth must be rejected, he suggests that a weaker conception of truth might replace the correspondence theory:

... something like a redundancy theory of truth is badly needed to replace it, something that will introduce minimal laws of logic (in particular, the law of non-contradiction) and make adhering to them a precondition for the rationality of evaluations. (2000: 99)

On Kuhn's later view, such a minimalist notion of truth is required to play a normative role in scientific discourse. The normative role of the notion of truth is to serve as the basis for a "language game whose rules forbid asserting both a statement and its contrary" (2000: 100). According to Kuhn, the nature of the scientific enterprise is such that scientists cannot accept both a statement and a statement that conflicts with it. Instead, they are required to accept or reject statements based on evidence that either supports or conflicts with the statements. In 
Kuhn's view, the notion of truth plays a crucial role in underpinning the practice of accepting or rejecting statements on the basis of evidence.

\section{Kuhn on incommensurability}

Along with his one-time colleague, Paul Feyerabend, Kuhn defended the claim that scientific theories or paradigms may be incommensurable. As we saw in section 2, in Structure Kuhn took the notion of incommensurability to have methodological, semantic, perceptual and perhaps ontological dimensions. However, in his later work Kuhn narrowed the focus of incommensurability to the semantic sphere. In doing so, Kuhn brought his use of the concept of incommensurability into line with that of Feyerabend, who restricted the notion of incommensurability to semantic relations between theories (e.g. Feyerabend 1981). In this section, I will explore the implications of the thesis of semantic incommensurability with respect to scientific realism. I will also briefly consider an anti-realist interpretation of incommensurability which understands Kuhn’s approach to science in neo-Kantian terms.

In Structure, Kuhn emphasized that transition between paradigms leads to significant conceptual change. Old concepts are rejected or altered, and new concepts are introduced. Because of such conceptual shift the vocabulary that scientists employ to express the concepts may be subject to semantic variation.

Within the new paradigm, old terms, concepts, and experiments fall into new relationships one with the other ... To make the transition to Einstein's universe, the whole conceptual web whose strands are space, time, matter, force, and so on, had to be shifted and laid down again on nature whole .... Communication across the revolutionary divide is inevitably partial. (2012: 148)

As a result of conceptual shift brought about by scientific revolution, the laws of an earlier paradigm may fail to reduce to laws of a later paradigm. As an example, Kuhn argues that, in a strict sense, Newtonian laws may not be derived from Einstein's physics. This is because 
the Einsteinian versions of Newton's laws employ terms such as 'space', 'time' and 'mass' in an Einsteinian rather than a Newtonian sense:

... the physical referents of these Einsteinian concepts are by no means identical with those of the Newtonian concepts that bear the same name. (Newtonian mass is conserved; Einsteinian is convertible with energy. Only at low relative velocities may the two be measured the same way, and even then they must not be conceived to be the same.) Unless we change the definition of the variables in the [Einsteinian versions of the laws], the statements we have derived are not Newtonian. (2012: 102)

In addition to variation in central theoretical concepts, Kuhn argued against the empiricist idea of a neutral observation language (2012: 125-9). As a result, semantic difference between paradigms may fail to be restricted to central theoretical concepts. Semantic variation between paradigms may extend to the vocabulary employed by scientists in their reports of observation and experiment.

In work subsequent to Structure, Kuhn came to think of incommensurability increasingly in terms of the inability to translate between the vocabularies employed by theories. At first, reflection on the nature of translation led Kuhn to compare incommensurability with Quinean indeterminacy of translation. But the comparison was not entirely apt. For Quine, there are multiple correct translations compatible with the evidence, whereas for Kuhn there is no correct translation between theories. In Kuhn's later work, incommensurability is taken to be localized failure of exact translation between inter-defined clusters of terms within the special vocabulary of theories (for the development of Kuhn's views of incommensurability, see Sankey 1993).

Kuhn's talk of conceptual change and untranslatability led Donald Davidson to take incommensurability as one of the main targets of his attack on the idea of a conceptual scheme (Davidson 1984). To argue that a language is untranslatable into another by providing examples of expressions that are unable to be translated is to court paradox. The very act of presenting an example of an untranslatable expression within the language into 
which it fails to be translatable shows that the expression is able to be translated into that language. For this and related reasons, Davidson argued that the very idea of a conceptual scheme is to be rejected as incoherent. Objections such as Davidson's led Kuhn to insist that the translation failure characteristic of incommensurability is not wholesale translation failure between natural languages or even the vocabulary of competing theories. It is restricted to subsets of the special vocabulary of theories (cf. Kuhn 2000: 35-6). This avoids the paradoxical implications that are the focus of Davidson's criticism, since a vocabulary may be shown to lack the resources possessed by another vocabulary without having to translate between them (see Sankey 1990).

Translation failure between theories is connected with the topic of the previous section. As we saw, Kuhn opposes the realist view of progress as advance on truth because of doubts about truth and convergence. In addition to the earlier considerations, Kuhn came to think that incommensurability militates against convergence. He suggests that claims of "science's zeroing in on, getting closer and closer to, the truth" are "meaningless" as a result of incommensurability (2000: 243). Because of the semantic variation which leads to inability to translate, "no shared metric is available to compare our assertions about force and motion with Aristotle's and thus to provide a basis for a claim that ours (or, for that matter, his) are closer to the truth” (2000: 244).

This brings us to the nub of the issue. Kuhn insisted that incommensurability does not entail incomparability. But there is a sense in which the content of incommensurable theories may not be compared. "There is no neutral language," he writes, "into which both of the theories as well as the relevant data may be translated for purposes of comparison” (2000: 204; cf. 189). Empirical predictions and other assertions made by rival theories using terms that differ in meaning are unable to be compared with respect to assertion or denial of the same proposition. A claim about the world made by one theory will neither assert nor deny 
the same thing as a claim of the other theory if the claims are expressed by means of terms that do not have the same meaning. But if it is impossible to compare the content of theories in this way, then it will not be possible to show that one theory makes more true claims than the other. Moreover, if the semantic variation is extensive, it may not be possible to show that in the transition between theories there is convergence on truth by means of a cumulative increase of truth about the same things. Thus, given the implications for comparison of content, inability to translate between incommensurable theories gives rise to further problems for a realist account of scientific progress as advance on truth.

But the claim that untranslatability entails incomparability of content trades on an ambiguity in the notion of meaning. As pointed out by Scheffler (1967: 54-66), it is important to distinguish between the sense and the reference of a term or expression. The distinction may be illustrated using Frege's famous example of 'Morning-Star' and 'EveningStar'. The two expressions differ in sense even though they have the same reference, viz. the planet Venus. Scheffler pointed out that in order for assertions made by competing theories to agree or disagree, the terms occurring in the assertions need only have the same reference. They need not have the same sense. Given this, the claim that meaning varies between theories does not entail that the content of the theories is unable to be compared. Provided only that the terms refer to the same things, the content of theories may be compared, whether or not the terms have the same sense. Thus, even if it is impossible to provide an exact translation of the claims of one theory using semantically equivalent vocabulary of the other theory, it may nevertheless be possible to compare what one theory says about the world with what the other theory says.

Scheffler's point about reference and content comparison was an important step in coming to grips with the problem of incommensurability. But, as traditionally understood, it is not just that sense and reference are distinct aspects of meaning. It was also held that sense 
determines reference. If we take the sense of an expression to be given by a description associated with the expression, the reference of the expression is the item (or set of items) that satisfies the description. For example, the word 'tiger' refers to those items which satisfy the description "large carnivorous, orange-coloured feline with black stripes found in the jungles of Asia”. The problem with reference depending on description in this way is that in cases of conceptual change in science the descriptive content associated with an expression may be subject to significant alteration. As a result, descriptions associated with a term employed by competing theories may be unable to be satisfied by the same things. This is evidently what Kuhn had in mind in claiming that Newtonian mass is conserved whereas Einsteinian is convertible with energy. The two descriptions may not be jointly satisfied. For this reason, the Newtonian term 'mass' must fail to have the same reference as the Einsteinian term 'mass'. In general, if reference is determined by description, it cannot be assumed that terms employed by semantically variant theories refer to the same things.

Recognition that the determination of reference by sense may lead to discontinuity of reference between theories led philosophers to explore causal theories of reference on which reference is not determined by description (e.g. Devitt 1979). If reference is determined by causal relation between speaker and the world, rather than by descriptive content associated with an expression, then reference will be insensitive to variation in descriptive content. Though this was a promising idea, it soon emerged that the reference of theoretical terms may not be determined simply by causal relation between speaker and world. For this reason, philosophers working on this topic have tended to endorse some variant of the causaldescriptive theory of reference on which both causal and descriptive elements contribute to the determination of reference (see, for example, Psillos 1999, chapter 12).

For scientific realists, appeal to the theory of reference has seemed the most promising approach to the problem of incommensurability. But it has been objected that the 
theory of reference is unable to serve as a neutral ground in the debate between scientific realists and defenders of incommensurability. In his influential interpretation of Kuhn, Paul Hoyningen-Huene (1993) has argued that Kuhn's metaphysical view is best understood in neo-Kantian terms. In describing change of paradigm, Kuhn sometimes characterized the experience of scientists as a change of world: e.g., "the historian may be tempted to exclaim that when paradigms change, the world itself changes with them” (2012: 110). Rather than take such claims literally, Hoyningen-Huene argued that they may be understood in terms of a Kantian distinction between the world-in-itself and the phenomenal world. On this view, what changes in scientific revolution is the phenomenal world inhabited by scientists. The world-in-itself, which lies beyond the epistemic reach of science, may be presumed to remain fixed between paradigms. On this interpretation, the terms of incommensurable paradigms refer to entities within the phenomenal worlds of the paradigms. For the realist to argue that there is continuity of reference between paradigms is to beg the question against the neoKantian anti-realist who treats reference as internal to the phenomenal world of a paradigm. (For a recent neo-Kantian approach to Kuhn that incorporates some realist themes, see Massimi 2015.)

\section{Conclusion}

In this chapter, I have explored the ways in which Kuhn's views are in tension with scientific realism. As we have seen, Kuhn's account of scientific progress enters into conflict with the realist view that progress consists in advance on truth. Kuhn's doubts about a match between theory and reality led him to reject the correspondence theory of truth which many realists

endorse. Further problems about scientific progress and an increase in truth also arise from Kuhn's ideas about incommensurability. 
But it should not be thought that Kuhn's views are comprehensively opposed to scientific realism. There is no reason for the scientific realist to deny that the evaluation of scientific theories is multi-criterial or to insist that the choice between theories must be based on an algorithm. Provided that the criteria of theory choice reliably promote the search for truth, the realist may accept much of what Kuhn says about the appraisal of theories. Moreover, there is no reason for the realist to deny that scientific progress may be thought of in evolutionary and problem-solving terms. Provided that theories at a later stage of evolution which display an increase in problem-solving effectiveness are also making headway toward the truth, the realist may agree that increased adaptation and problemsolving ability are features of scientific progress. Finally, there is no need for the realist to deny that substantial conceptual change takes place in the history of science. The realist may well wish to say that such changes bring the conceptual apparatus of science into closer accord with real divisions in nature. But conceptual change as such is not something that the realist need resist.

\section{References}

Bird, A. (2000) Thomas Kuhn, Chesham: Acumen Press.

Davidson, D. (1984) “On the Very Idea of a Conceptual Scheme”, in Inquiries into Truth and Interpretation, Oxford: Oxford University Press, pp. 183-98.

Devitt, M. (1979) “Against Incommensurability”, Australasian Journal of Philosophy 57: 2950. 
Feyerabend, P. (1981) “Explanation, Reduction and Empiricism,” in Realism, Rationalism and Scientific Method: Philosophical Papers, Volume 1, Cambridge: Cambridge University Press, pp. 44-96.

Hoyningen-Huene, P. (1993) Reconstructing Scientific Revolutions: Thomas S. Kuhn's Philosophy of Science, Chicago: University of Chicago Press.

Kuhn, T.S. (1977) “Objectivity, Value Judgment and Theory Choice”, in The Essential Tension, Chicago: University of Chicago Press, pp. 320-39.

Kuhn, T.S. (2000) The Road Since STRUCTURE, Chicago: University of Chicago Press.

Kuhn, T.S. (2012) The Structure of Scientific Revolutions (4 ${ }^{\text {th }}$ ed.), Chicago: University of Chicago Press.

Lakatos, I. (1970) “Falsification and the Methodology of Scientific Research Programmes” in I. Lakatos and A. Musgrave (eds.) Criticism and the Growth of Knowledge, Cambridge: Cambridge University Press, pp. 91-196.

Massimi, M. (2015) "Walking the Line: Kuhn Between Realism and Relativism”, in W.J. Devlin and A. Bokulich (eds.), Kuhn's Structure of Scientific Revolutions - 50 Years On, Springer International Publishing Switzerland, pp. 135-52.

K.R. Popper, "Normal Science and its Dangers” in I. Lakatos and A. Musgrave (eds.), Criticism and the Growth of Knowledge, Cambridge: Cambridge University Press, pp. 51-8.

Psillos, S. (1999), Scientific Realism: How Science Tracks Truth, London: Routledge.

Sankey, H. (1990) “In Defence of Untranslatability,” Australasian Journal of Philosophy 68: $1-21$. 
Sankey, H. (1993) “Kuhn’s Changing Concept of Incommensurability,” British Journal for the Philosophy of Science 44: 759-74.

Scheffler, I. (1967) Science and Subjectivity, Indianapolis: Bobbs-Merrill.

Shapere, D. (1964), “The Structure of Scientific Revolutions”, The Philosophical Review 73: 383-94.

\section{Further Reading}

In this chapter, I have sought to cover those aspects of Kuhn's work which intersect with central themes of scientific realism. For broader coverage of Kuhn, the following two recent anthologies provide an excellent introduction to contemporary scholarly work on Kuhn. V. Kindi and T. Arabatzis (eds.) Kuhn's The Structure of Scientific Revolutions Revisited (New York: Routledge, 2012). W. J. Devlin and A. Bokulich (eds.), Kuhn's Structure of Scientific Revolutions - 50 Years On (Springer International Publishing Switzerland, 2015). 